Jpn J Human Genet 41, 381-389, 1996

\title{
DETECTION OF ANEUPLOIDY IN HUMAN SPERMATOZOA USING FLUORESCENCE IN SITU HYBRIDIZATION (FISH)
}

\author{
He Hu, Norio Miharu, ${ }^{*}$ Tomoya Mizunoe, Yoshiharu NaKaoka, \\ Etsuji OKamoto, and Koso OHama
}

Department of Obstetrics and Gynecology, Hiroshima University School of Medicine, 1-2-3 Kasumi, Minami-ku, Hiroshima 734, Japan

\begin{abstract}
Summary Fluorescence in situ hybridization (FISH) with chromosome specific alpha-satellite DNA probes was used to estimate the rates of aneuploidy of chromosomes 1, 17, 18, $\mathrm{X}$ and $\mathrm{Y}$ in human ejaculated sperm. Sperm samples were collected from six donors, and biotinylated DNA probes, D1Z5, D17Z1, D18Z1, DXZ1 and DYZ3 were hybridized to interphase sperm which had been pretreated with dithiothreitol to expand their nuclei. A minimum of 3,000 sperm per donor were analyzed. The hybridization efficiency was $99.68 \%$ for all the five probes. The frequencies of aneuploidy for chromosomes 1,17 and 18 were $0.65 \%$, $0.66 \%$, and $0.61 \%$, respectively. For XX- and YY-sperm the frequencies were $0.28 \%$ and $0.27 \%$, respectively. To estimate the diploidy and disomy rates, a mixture of $\mathrm{D} 17 \mathrm{Zl}$ and $\mathrm{D} 18 \mathrm{Zl}$ were used as probes, and the frequency of diploid sperm was calculated to be $0.27 \%$. After subtraction of the diploidy rate, the disomy rates for chromosomes 1,17 , and 18 were estimated to be $0.38 \%, 0.39 \%$ and $0.33 \%$, respectively. The proportion of $\mathrm{X}$ - and Y-bearing sperm were $49.90 \%$ and $49.66 \%$, consistent with an expected 1: 1 ratio.
\end{abstract}

Key Words sperm, interphase, aneuploidy, chromosome, fluorescence in situ hybridization

\section{INTRODUCTION}

Numerical aberrations of human autosomes and sex chromosomes account for a significant proportion of chromosome abnormalities. Although the majority of aneuploidy arises during meiosis in the female, it also occurs in the male (Hassold and Sherman, 1993). Thus, it is important to characterize the occurrence of aneuploidy in the sperm. In 1978, Rudak et al. reported a new cytogenetic

Received August 8, 1996; Revised version accepted October 7, 1996.

* To whom correspondence should be addressed. 
technique using human sperm/hamster egg interactions which first permitted a direct analysis of the chromosomal constitution in individual human sperm (Rudak et al., 1978). In this way, human sperm chromosomes have been studied for both numerical and structural aberrations (Brandriff et al., 1984; Martin et al., 1982; Kamiguchi and Mikamo, 1986). However, this method is labor intensive and time consuming, and may reflect natural meiotic selection, since only fertilized eggs can be studied. Furthermore, it is difficult to evaluate the frequency of polyploidy in sperm because of the occurrence polyspermic fertilizations (Martin et al., 1982). Over the past several years, the fluorescence in situ hybridization (FISH) technique has widely been used to identify chromosomal abnormalities in both metaphase and interphase cells. However, sperm obtained from ejaculation are too condensed to get an efficient probe hybridization (Joseph et al., 1984).

In the present study, we utilized a method before hybridization to expand the sperm nuclei and improve detection of aneuploidy in ejaculated sperm. With this method, we studied the aneuploidy rates of chromosomes $1,17,18, \mathrm{X}$ and $\mathrm{Y}$ in sperm from six normal men.

\section{MATERIALS AND METHODS}

Slide preparation. Semen samples were obtained from six healthy Japanese donors, aged 21 to 23 years. Prior to FISH, semen analysis (concentration, motility rate and volume) was performed according to the standard procedures (WHO, 1987), and all components were within the normal range. Samples were incubated at $37^{\circ} \mathrm{C}$ for $30 \mathrm{~min}$, then diluted in Hank's balanced salt solution (Gibco, USA), and centrifuged at $2,000 \mathrm{rpm}$ for $8 \mathrm{~min}$. The pellet was fixed in fresh fixative (methanol: acetic acid, $3: 1$ ) at $-20^{\circ} \mathrm{C}$ for $20 \mathrm{~min}$. After two rinses with the fixative, sperm suspensions were dropped onto clean glass slides and air dried. the slides were stored at $-20^{\circ} \mathrm{C}$ until pretreatment and denaturation for FISH.

Pretreatment of sperm before FISH. Slides were put into 0.6-1.5\% dithiothreitol (DTT) (Sigma, USA) solutions at $37^{\circ} \mathrm{C}$ for $3-5 \mathrm{~min}$, then the slides were rinsed with water and air dried.

Fluorescence in situ hybridization. Alpha-satellite DNA probes, D1Z5, D17Z1, D18Z1, DXZ1, and DYZ3 (Oncor, USA), which are specific for chromosomes $1,17,18, X$, and $Y$, respectively, were used according to the manufacturer's protocol with minor modifications. To estimate the frequency of diploidy, a mixture of $\mathrm{D} 17 \mathrm{Z} 1$ and $\mathrm{D} 18 \mathrm{Z} 1$ probes (single color) were used. The hybridization solution consisted of $50 \%$ formamide, $5 \%$ dextran sulfate, and DNA probe (10 ng) were denatured at $70^{\circ} \mathrm{C}$ for $10 \mathrm{~min}$ prior to hybridization. Sperm slides were also denatured by immersion in $70 \%$ formamide, $2 \times \mathrm{SSC}$ at $70^{\circ} \mathrm{C}$ for $5 \mathrm{~min}$, then dehydrated in an ethanol series and air-dried. Hybridizations were performed at $37^{\circ} \mathrm{C}$ overnight. Post washings were carried out by immersion in $65 \%$ formamide and $2 \times \mathrm{SSC}$ at $43^{\circ} \mathrm{C}$ for 1 to $3 \mathrm{~min}$. Detection was achieved using alternating cycles 


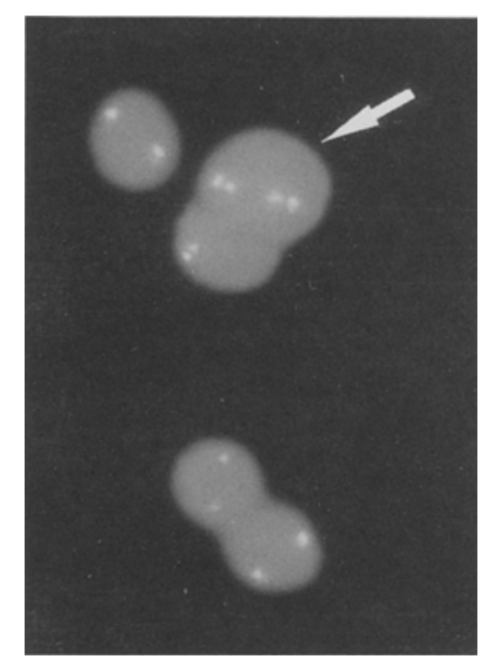

Fig. 1. Diploid sperm nucleus (arrow) showing two D17Z1-signals and two D18Z1signals.

of fluorescein isothiocyanate (FITC)-conjugated avidin and anti-avidin antibody each at $37^{\circ} \mathrm{C}$ for $20 \mathrm{~min}$, followed by one cycle of the FITC-conjugated avidin. After final avidin treatment, $0.25 \%$ propidium iodide was applied for counter stain. Then an anti-fade reagent (Oncor) was applied onto the slides, which were covered with cover slips and sealed with rubber cement.

Microscopic analysis. Hybridization signals on sperm nuclei were examined under a Nikon Optiphot microscope with a Nikon B2-A filter. The fluoresceinlabeled hybridization signals appeared as yellow-green spots against the orange background of the propidium iodide-stained chromatins. At least 3,000 sperm were analyzed for each sample with each probe except Donor 2 for DYZ3. Sperm with two distinct signals were scored as hyperhaploid, which could indicate either disomy or diploidy. Sperm with four distinct signals using the alpha-satellite 17/ 18 probe cocktail were scored as diploid (Fig. 1). After subtracting the diploidy rate from the hyperhaploidy rate, the disomy rate was calculated from the residual. Because XY-bearing sperm were not observable with the single-color scoring system, total sex-chromosome disomy rates could not be obtained. The XX- or YY-bearing sperm frequencies were counted as the number of sperm with two signals among all sperm counted which would reflect combined frequencies for disomic and diploid sperm.

\section{RESULTS}

After pretreatment of sperm nuclei with DTT, sperm heads were expanded to 2 to 3 times as large as their original size. Of a total of $91,040 \mathrm{sperm}, 55,000$ were 
examined for autosomes (chromosomes 1, 17, and 18) and 36,040 for sex-chromosomes. Based on the observation that $0.35 \%$, ranging from $0.2 \%$ to $0.6 \%$, of sperm lacked FISH signals, the hybridization efficiency was calculated to be greater than 99.65\%. The mean frequencies of hyperhaploid sperm for chromosomes 1,17 , and

Table 1. Frequency of DIZ5, DI7ZI and D18Z1 FISH signals in sperm nuclei.

\begin{tabular}{clcrrr}
\hline \multirow{2}{*}{ Donor } & Probe & $\begin{array}{c}\text { Number of sperm } \\
\text { examined }\end{array}$ & \multicolumn{3}{c}{ Number of signals (\%) } \\
\hline 1 & D1Z5 & 3,000 & $6(0.20)$ & $2,973(99.10)$ & $21(0.70)$ \\
& D17Z1 & 3,000 & $9(0.30)$ & $2,967(98.90)$ & $24(0.80)$ \\
\multirow{2}{*}{2} & D18Z1 & 3,000 & $19(0.60)$ & $2,960(98.67)$ & $21(0.70)$ \\
& D1Z5 & 3,000 & $7(0.23)$ & $2,976(99.20)$ & $17(0.56)$ \\
& D17Z1 & 3,000 & $8(0.27)$ & $2,975(99.17)$ & $17(0.56)$ \\
3 & D18Z1 & 3,000 & $6(0.20)$ & $2,981(99.37)$ & $13(0.43)$ \\
& D1Z5 & 3,300 & $9(0.27)$ & $3,269(99.06)$ & $22(0.66)$ \\
& D17Z1 & 3,300 & $8(0.24)$ & $3,272(99.15)$ & $20(0.60)$ \\
4 & D18Z1 & 3,000 & $9(0.30)$ & $2,974(99.13)$ & $17(0.57)$ \\
& D1Z5 & 3,000 & $9(0.30)$ & $2,974(99.13)$ & $17(0.57)$ \\
& D17Z1 & 3,000 & $11(0.37)$ & $2,972(99.07)$ & $17(0.57)$ \\
5 & D18Z1 & 3,000 & $18(0.60)$ & $2,966(99.87)$ & $16(0.53)$ \\
& D1Z5 & 3,400 & $9(0.26)$ & $3,371(99.15)$ & $20(0.59)$ \\
& D17Z1 & 3,000 & $8(0.27)$ & $2,974(99.13)$ & $18(0.60)$ \\
6 & D18Z1 & 3,000 & $12(0.40)$ & $2,970(99.00)$ & $18(0.60)$ \\
& D1Z5 & 3,000 & $7(0.23)$ & $2,969(98.97)$ & $24(0.80)$ \\
& D17Z1 & 3,000 & $10(0.40)$ & $2,965(98.83)$ & $25(0.83)$ \\
& D18Z1 & 3,000 & $12(0.32)$ & $2,964(98.80)$ & $24(0.80)$ \\
\hline \multirow{2}{*}{ Total } & & 55,000 & $177(0.35)$ & $54,472(99.04)$ & $351(0.64)$ \\
\hline & & & & &
\end{tabular}

Table 2. Frequency of DXZ3 and DYZ1 FISH signals in sperm nuclei.

\begin{tabular}{|c|c|c|c|c|c|c|c|c|}
\hline \multirow[t]{2}{*}{ Donor } & \multirow{2}{*}{$\begin{array}{l}\text { Number } \\
\text { of sperm } \\
\text { examined }\end{array}$} & \multicolumn{3}{|c|}{$\begin{array}{c}\text { Number of signals for } \mathrm{DXZ1} \\
\text { (\%) }\end{array}$} & \multirow{2}{*}{$\begin{array}{l}\text { Number } \\
\text { of sperm } \\
\text { examined }\end{array}$} & \multicolumn{3}{|c|}{$\begin{array}{c}\text { Number of signals for DYZ3 } \\
(\%)\end{array}$} \\
\hline & & 0 & 1 & 2 & & 0 & 1 & 2 \\
\hline 1 & 3,000 & $\begin{array}{l}1,484 \\
(49.46)\end{array}$ & $\begin{array}{l}1,507 \\
(50.23)\end{array}$ & $\begin{array}{l}9 \\
(0.30)\end{array}$ & 3,000 & $\begin{array}{l}1,501 \\
(50.03)\end{array}$ & $\begin{array}{l}1,492 \\
(49.73)\end{array}$ & $\begin{array}{l}7 \\
(0.23)\end{array}$ \\
\hline 2 & 3,000 & $\begin{array}{l}1,497 \\
(49.90)\end{array}$ & $\begin{array}{l}1,495 \\
(49.83)\end{array}$ & $\begin{array}{l}8 \\
(0.27)\end{array}$ & 2,940 & $\begin{array}{l}1,486 \\
(50,54)\end{array}$ & $\begin{array}{l}1,445 \\
(49.14)\end{array}$ & $\begin{array}{l}9 \\
(0.30)\end{array}$ \\
\hline 3 & 3,000 & $\begin{array}{l}1,516 \\
(50.53)\end{array}$ & $\begin{array}{l}1,475 \\
(49.16)\end{array}$ & $\begin{array}{l}9 \\
(0.30)\end{array}$ & 3,000 & $\begin{array}{l}1,503 \\
(50.10)\end{array}$ & $\begin{array}{l}1,487 \\
(49.56)\end{array}$ & $\begin{array}{l}10 \\
(0.23)\end{array}$ \\
\hline 4 & 3,100 & $\begin{array}{l}1,552 \\
(50.16)\end{array}$ & $\begin{array}{l}1,541 \\
(49,70)\end{array}$ & $\begin{array}{l}7 \\
(0.23)\end{array}$ & 3,100 & $\begin{array}{l}1,499 \\
(49.97)\end{array}$ & $\begin{array}{l}1,496 \\
(49.87)\end{array}$ & $\begin{array}{l}5 \\
(0.17)\end{array}$ \\
\hline 5 & 3,000 & $\begin{array}{l}1,488 \\
(49.60)\end{array}$ & $\begin{array}{l}1,503 \\
(50.10)\end{array}$ & $\begin{array}{l}9 \\
(0.30)\end{array}$ & 3,000 & $\begin{array}{l}1,497 \\
(49.90)\end{array}$ & $\begin{array}{l}1,496 \\
(49.87)\end{array}$ & $\begin{array}{l}7 \\
(0.23)\end{array}$ \\
\hline 6 & 3,000 & $\begin{array}{l}1,478 \\
(49.26)\end{array}$ & $\begin{array}{l}1,513 \\
(50.43)\end{array}$ & $\begin{array}{l}9 \\
(0.30)\end{array}$ & 3,000 & $\begin{array}{l}1,496 \\
(49.86)\end{array}$ & $\begin{array}{l}1,494 \\
(49.80)\end{array}$ & $\begin{array}{l}10 \\
(0.33)\end{array}$ \\
\hline Total & $18,100^{\circ}$ & $\begin{array}{l}9,015 \\
(49.82)\end{array}$ & $\begin{array}{l}9,034 \\
(49.90)\end{array}$ & $\begin{array}{l}51 \\
(0.28)\end{array}$ & 17,940 & $\begin{array}{l}8,982 \\
(50.06)\end{array}$ & $\begin{array}{l}8,910 \\
(49.66)\end{array}$ & $\begin{array}{l}48 \\
(0.27)\end{array}$ \\
\hline
\end{tabular}


Table 3. Frequency of diploid sperm in 6 donors.

\begin{tabular}{ccc}
\hline Donor & Number of sperm examined & Diploid sperm (\%) \\
\hline 1 & 3,000 & $7(0.23)$ \\
2 & 3,000 & $8(0.27)$ \\
3 & 3,000 & $11(0.37)$ \\
4 & 3,000 & $5(0.17)$ \\
5 & 3,000 & $7(0.23)$ \\
6 & 3,000 & $11(0.37)$ \\
\hline Total & 18,000 & $49(0.27)$ \\
\hline
\end{tabular}

Table 4. Frequency (\%) of disomic sperm for chromosomes 1, 17 and 18.

\begin{tabular}{cccccccc}
\hline Chromosome & Donor 1 & Donor 2 & Donor 3 & Donor 4 & Donor 5 & Donor 6 & Mean \\
\hline 1 & 0.47 & 0.30 & 0.30 & 0.40 & 0.36 & 0.43 & 0.38 \\
17 & 0.57 & 0.30 & 0.24 & 0.40 & 0.37 & 0.47 & 0.39 \\
18 & 0.47 & 0.17 & 0.20 & 0.37 & 0.37 & 0.43 & 0.33 \\
\hline
\end{tabular}

18 were $0.65 \%, 0.66 \%$, and $0.61 \%$, respectively (Table 1 ). The frequencies of $\mathrm{X}$ bearing and Y-bearing sperm were $49.90 \%$ and $49.66 \%$, respectively (Table 2 ). A ratio of $\mathrm{X}$ - to $\mathrm{Y}$-bearing sperm was not significantly different from $1: 1(\mathrm{p}=0.345)$. The mean frequency of XX-sperm was $0.28 \%$ and that of $Y Y$-sperm was $0.27 \%$ (Table 2). The mean frequency of diploid sperm was $0.27 \%$ (Table 3 ). The mean frequency of disomic sperm for chromosomes 1,17 , and 18 were $0.38 \%, 0.39 \%$, and $0.33 \%$, respectively (Table 4 ). Chi-square analysis was performed to compare disomic and diploid sperm rates among the donors and among the autosomes. There were no significant differences in the frequencies of disomy for chromosome $1(\mathrm{p}=0.84)$, chromosome $17(\mathrm{p}=0.64)$ and chromosome $18(\mathrm{p}=0.48)$ among the donors. Likewise, there was no significant difference in the frequency of diploidy rates $(p=0.62)$ among the donors. In addition, there was no significant difference in the frequencies of disomy among the different autosomes studied $(p=0.74)$.

\section{DISCUSSION}

The chromatin of the mammalian sperm is packed in a condensed and inactive state by intra- and inter-protamine disulfide bridges (Balhorn, 1982; Rodman et al., 1982). To apply the FISH techniques successfully to human spermatozoa, it is critical to open the disulfide bridges to decondense sperm nuclear chromatin (Wyrobek et al., 1990). Earlier studies did not use optimal pretreatment methods to enhance decondensation of the nuclei. Thus, the older methods permitted reduced access of probes to the nucleus and therefore lower hybridization efficiencies (Burns et al., 1985; Joseph et al., 1984). Lower hybridization efficiencies tended to result in under-estimation of disomy or diploidy rates. Our pretreatment method of sperm with DTT is simple and easy, compared with 
other protocols (Robbins et al., 1993; Holmes and Martin, 1993; Han et al, 1992; Williams et al., 1993). Previous investigators used DTT for longer treatment time and sometimes required subsequent treatment with a lithium salt. In this study, we used DTT at a relatively higher temperature $\left(37^{\circ} \mathrm{C}\right)$ and consequently reduced the time of pretreatment to $5 \mathrm{~min}$. Sperm heads were expanded to 2 to 3 times as large as their original size, with an increased hybridization efficiency of $99.65 \%$. Signals were very clear and intense, and diffusion phenomenon was minimized.

With a single-color system, both disomic and diploid sperm nuclei produce two signals. A number of investigators tried to utilize large head size of sperm as a criterion to distinguish diploid sperm from disomic sperm (Coonen et al., 1991; Han et al., 1992). However, Carothers and Beatty (1975) showed that the cell size and morphology do not always correlate with DNA-based determinations of ploidy in sperm. Miharu et al. (1994) also observed a lack of correlation between cell size and ploidy in some cells by FISH, although a pretreatment to expand sperm heads may have contributed to the variability in cell size. In the present study, a probe cocktail for chromosomes 17 and 18 was used to identify diploid sperm and to estimate the diploidy and disomy rates. Although our system could not allow simultaneous examinations of both disomic and diploid sperm on the same slide, it is now available by means of two-color FISH, and no longer requires innovative or expensive techniques.

The disomy rate $(0.38 \%)$ for chromosome 1 in this study is similar to that $(0.41 \%)$ in the report of Guttenbach and Schmid (1991), while higher than those in the previous reports (Robbins et al., 1993; Miharu et al., 1994) (Table 5). The disomy rate $(0.39 \%)$ for chromosome 17 in this study is comparable to those $(0.33 \%$ and $0.31 \%$ ) by Han et al. (1992) and by Guttenbach et al. (1994a), while higher than that $(0.13 \%)$ in the report of Bischoff et al. (1994) (Table 5). The disomy rate $(0.33 \%)$ obtained for chromosome 18 is comparable to those $(0.36 \%$ and $0.25 \%)$ by Guttenbach et al. (1994b) and by Bischoff et al. (1994), while higher than that

Table 5. Summary of studies of disomy and diploidy frequencies (\%) using FISH,

\begin{tabular}{|c|c|c|c|c|}
\hline \multirow{2}{*}{ Study } & \multicolumn{4}{|c|}{ Chromosomes } \\
\hline & 1 & 17 & 18 & Diploid \\
\hline Guttenbach and Schmid (1991) & 0.41 & & & \\
\hline Han et al. (1992) & & 0.33 & & 0.37 \\
\hline Williams et al. (1993) & & & 0.08 & 0.34 \\
\hline Robbins et al. (1993) & 0.14 & & & \\
\hline Bischoff et al. (1994) & & 0.13 & 0.25 & \\
\hline Guttenbach et al. (1994a) & & 0.31 & & \\
\hline Guttenbach et al. (1994b) & & & 0.36 & \\
\hline Miharu et al. (1994) & 0.14 & & & 0.23 \\
\hline Griffin et al. (1995) & & & 0.04 & \\
\hline This study & 0.38 & 0.39 & 0.33 & 0.27 \\
\hline
\end{tabular}


(0.08\% and 0.04\%) by Williams et al. (1993) and by Griffin et al. (1995) (Table 5). On the contrary, the diploidy rate in this study is comparable to those of other investigators (Han et al., 1992; Williams et al., 1993; Miharu et al., 1994) (Table 5). The discrepancies in the disomy rates among investigators may have been due to different sample sizes and different scoring criteria of disomic sperm. Inclusion of sperm into the disomic sperm whose signals are close together by chance due to split signals or replicated chromosomes may lead to higher estimated rates of disomy. Since we did not simultaneously use $X$ - and $Y$-specific probes, we could not analyze the $\mathrm{XY}$-sperm rate. The rates of $\mathrm{XX}$ - and $\mathrm{YY}$-sperm in this study reflect a combination of disomy resulting from meiosis II error and diploidy. Thus, the XX- and YY-sperm frequencies $(0.28 \%$ and $0.27 \%)$ estimated in this study are higher than those reported previously (Wyrobek et al., 1990; Robbins et al., 1993; Griffin et al., 1995) (Table 5). The rates of XX-and YY-diploid sperm are needed to calculate the true rates of disomy for sex chromosomes. Williams et al. (1993) reported that about $75 \%$ of diploid sperm were produced in meiosis II error. Using this datum, mean frequencies of XX- and YY-sperm in this study are calculated to be $0.18 \%$ and $0.15 \%$, respectively. The disomy rates for autosomes in this study are generally higher than those estimated from conventional cytogenetic studies on hamster eggs (Martin, 1985; Brandriff et al., 1985). The discrepancies of the disomy rates between FISH and karyotype studies may be due to the limited number of total sperm in the karyotype studies. Under 100 sperm could be studied per donor at one time in karyotype studies. With an approximate disomy frequency of one per 10,000 sperm, the sample size obtained by karyotype study is relatively small. Furthermore, the hamster egg may act as a barrier against some sperm with chromosomal abnormalities. In order to know an effect of infertility status on cytogenetic abnormality of sperm, Miharu et al. (1994) studied disomy frequencies both in infertile and fertile populations, and could not find any differences between the two populations. However, Wyrobek et al. (1994) did not find any differences in the frequencies of disomic sperm between FISH and karyotype studies using the hamster egg test. Further studies on all chromosomes with larger sample sizes are needed in this area. We could not find any differences in the disomy rates among the different autosomes studied in this paper $(p=0.748)$. Although Williams et al. (1993) reported a significant increase of the XY-sperm rate by FISH experiments as well as karyotyping, no study on the comparison of the disomy rates among all chromosomes has yet been reported. Thus, further studies are also needed.

In summary we have utilized FISH to study aneuploidy rates in sperm with a simple pretreatment method which optimizes sperm head swelling and hybridization efficiency. This is the first report with Japanese male samples using large sample sizes and high hybridization efficiency. Multicolor FISH using mixtures of probes simultaneously should be done to resolve the true frequencies of disomic and diploid sperm. 
Acknowledgments We wish to thank Dr. Robert G. Best for his reviewing the manuscript. This study was supported in part by Grants-in-Aid for Scientific Research from the Ministry of Education, Science, Sports and Culture of Japan (Nos. 06771338 and 07671788).

\section{REFERENCES}

Balhorn R (1982): A model for the structure of chromatin in mammalian sperm. J Cell Biol 93: $298-305$

Bischoff FZ, Nguyen DD, Burt KJ, Schaffer LG (1994): Estimates of aneuploidy using multicolor fluorescence in situ hybridization on human sperm. Cytogenet Cell Genet 66: 237-243

Brandriff B, Cordon L. Ashworth L, Watchmaker G, Carrano A, Wyrobek A (1984): Chromosomal abnormalities in human sperm: comparisons among four healthy men. Hum Genet 66: 193-201

Brandriff B, Gordon L, Ashworth L, Watchmaker G, Moore D, Wyrobek A, Carrano A (1985): Chromosomes of human sperm. variability among normal individuals. Hum Genet 70: 18-24

Burns J, Chan VTM, Jonassan JA, Fleming KA, Taylor S, Mcgree JOD (1985): Sensitive system for visualizing biotinylated DNA probes hybridized in situ: Rapid sex determination of intact cells. J Clin Pathol 38: 1085-1092

Carothers AD, Beatty RA (1975): The recognition and incidence of haploid and polyploid spermatozoa in man, rabbit, and mouse. J Reprod Fertil 44: 487-500

Coonen E, Pieters MHEC, Dumoulin JCM, Meyer H, Evers JLH, Ramaekers FCS, Feraedis JPM (1991): Nonisotopic in situ hybridization as a method for nondisjunction studies in human spermatozoa. Mol Reprod Dev 28: 18-22

Griffin DK, Abruzzo MA, Millie EA, Sheean LA, Feingold E, Sherman SL, Hassold TJ (1995): Non-disjunction in human sperm: evidence for an effect of increasing paternal age. Hum Mol Genet 4: $2227-2232$

Guttenbach M, Schmid M (1991): Non-isotopic detection of chromosome 1 in human meiosis and demonstration of disomic sperm nuclei. Hum Genet 87: 261-265

Guttenbach M, Schakowski R, Schmid M (1994a): Incidence of chromosome 3, 7, 10, 11, 17, and $\mathrm{X}$ disomy in mature human sperm nuclei as determined by non-radioactive in situ hybridization. Hum Genet 93: 7-12

Guttenbach M, Schakowski R, Schmid M (1994b): Incidence of chromosome 18 disomy in human sperm nuclei as detected by nonisotopic in situ hybridization. Hum Genet 93: 421-423

Han TL, Webb GC, Flaherty SP, Correll A, Matthews CD, Ford JH (1992): Detection of chromosome 17- and $\mathrm{X}$-bearing human spermatozoa using fluorescence in situ hybridization. Mol Reprod Dev 33: 189-194

Hassold TJ, Sherman SL (1993): The origin of non-disjunction in humans. Vol 11. Cambridge Univ Press, Cambridge, pp 313-322

Holmes JM, Martin RH (1993): Aneuploidy detection in human sperm nuclei using fluorescence in situ hybridization. Hum Genet 91: 20-24

Joseph AM, Gosden JR, Chandley AC (1984): Estimation of ancuploidy levels in human spermatozoa using chromosome specific probes and in situ hybridization. Hum Genet 66: $234-238$

Kamiguchi Y, Mikamo K (1986): An improved efficient method for analyzing human sperm chromosomes using zona-free hamster ova. Am J Hum Genet 38: 724-740

Martin RH, Lin CC, Balkan W, Burns K (1982): Direct chromosomal analysis of human spermatozoa: Preliminary results from 18 normal men. Am J Hum Genet 34: 459-468

Martin RH (1985): Chromosomal abnormalities in human sperm. In: Dellarco VL, Voytek PE, Hollaender A (eds). Aneuploidy etiology and mechanisms. Basic life sciences. Vol 36. Plenum Press, New York, pp 91-102

Miharu N, Best RG, Young SR (1994): Numerical chromosome abnormalities in spermatozoa of fertile and infertile men detected by fluorescence in situ hybridization. Hum Genet 93: 502 506 
Robbins WA, Segrave R, Pinkel D, Wyrobek AJ (1993): Detection of aneuploid human sperm by fluorescence in situ hybridization: evidence for a donor difference in frequency of sperm disomic for chromosomes 1 and Y. Am J Hum Genet 52: 799-807

Rodman TC, Pruslin FH, Allfrrey VG (1982): Mechanisms of displacement of sperm basic nuclear proteins in mammals. An in vitro simulation of post fertilization results. J Cell Sci 53: $227-244$

Rudak E, Jacobs PA, Yanagimachi R (1978): Direct analysis of chromosome constitution of human spermatozoa. Nature 274: 911-913

Williams BJ, Ballenger CA, Malter HE, Bishop F, Tucker M, Zwingmañ TA, Hassold TJ (1993): Non-disjunction in human sperm: results of fluorescence in situ hybridization studies using two and three probes. Hum Mol Genet 2: 1929-1936

World Health Organization (1987): WHO laboratory manual for the examination of human semen and semen-cervical mucus interaction. 2nd ed. Cambridge Univ Press, New York, pp $3-10$

Wyrobek AJ, Alhborn T, Balhorn R, Stanker L, Pinkel D (1990): Fluorescence in situ hybridization to Y chromosome in decondensed human sperm nuclei. Mol Reprod Dev 27: 200-208

Wyrobek AJ, Robbins WA, Mehraein Y, Pinkel D, Weier HU (1994): Detection of sex chromosomal aneuploidies $\mathrm{X}-\mathrm{X}, \mathrm{Y}-\mathrm{Y}$, and $\mathrm{X}-\mathrm{Y}$ in human sperm using two-chromosome fluorescence in situ hybridization. Am J Med Genet 53: 1-7 